\title{
SEPARAÇÃo de PODERES E AS TEORIAS INTERNA E EXTERNA dOS DIREITOS FUNDAMENTAIS: DIREITOS SOCIAIS E A INAPLICABILIDADE DA TEORIA EXTERNA
}

Separation of powers and theories internal and external of fundamental rights: social rights and the inapplicability of external theory

\section{Richard Pae Kim}

Doutor e Mestre em Direito pela USP. Pós-doutorado em políticas públicas pela UNICAMP. Professor dos Cursos de Graduação e de Mestrado em Direito da UNIMEP-SP. Professor dos cursos de pós-graduação da Escola Paulista da Magistratura. Juiz de Direito/SP. Juiz Auxiliar de Gabinete no Supremo Tribunal Federal. E-mail: rppk@uol.com.br

CONVIDADO

RECEBIDO EM:12/02/2016

AProvado EM:12/02/2016

DOI: $10.5585 /$ RDB.V10I5.347

\section{Resumo}

Cinco são os vetores que foram considerados no desenvolvimento deste trabalho: a) a necessária distinção de tratamento a ser dado aos direitos fundamentais decorrentes das liberdades clássicas de um lado e, de outro lado, aos direitos fundamentais de segunda dimensão; b) a premissa de que inexistem direitos fundamentais absolutos; c) a certeza de que a interpretação da norma deve observar os critérios científicos, inclusive na definição da regra definitiva no caso de colisão de princípios de direitos fundamentais; d) a obrigação constitucional de evitar o abuso de direito; e) e, por fim, que há de se resguardar, sempre, a separação dos Poderes da República dentro dos parâmetros fixados em nossa Carta. Analisados o conteúdo e a pertinência em nosso sistema jurídico das teorias externa e interna das restrições aos direitos fundamentais (de primeira e de segunda dimensão), e descritos os seus limites, chega-se à conclusão de que se mostra mais adequada a utilização da teoria externa para se admitir a aplicação de restrições às liberdades e que faz mais sentido utilizar-se a teoria interna para a identificação dos limites aos direitos fundamentais sociais (inaplicabilidade, pois, da teoria externa). Por fim, infere-se que tanto na restrição como no levantamento dos limites dos direitos fundamentais há de se respeitar, sempre, os requisitos da legalidade, da proporcionalidade e da proibição das 
decisões casuísticas.

PalaVras-chave:: Direitos fundamentais; Liberdades; DiReitos Sociais; TEORIA INTERNA; TEORIA EXTERNA; LIMITES; RESTRIÇÕES; SEPARAÇÃO DE PODERES.

\section{Abstract}

Five are the vectors that were considered in the development of this paper: a) the necessary treatment of distinction to be given to the fundamental rights conferred by the classic freedoms on the one hand and, on the other hand, the fundamental rights of second dimension; $b$ ) the assumption that there are no absolute fundamental rights; c) make sure that the interpretation of the rule must meet the scientific criteria, including the establishment of the final rule in the case of collision of fundamental rights principles; d) a constitutional obligation to prevent the abuse of rights; e) and, finally, it is necessary always to protect the separation of government powers within the parameters set in our Charter. Analyzed the content and relevance in our legal system of internal and external theories of restrictions on fundamental rights (first and second dimension), and described its limits, one comes to the conclusion that seems more appropriate to use the external theory to allow the application of restriction on freedoms and that makes more sense to use the internal theory to identify the limits to social fundamental rights. Finally, it appears that both the restriction as in the identification of limits of fundamental rights it is necessary to satisfy the requirements of legality, proportionality and the prohibition of the caseby-case decisions.

KEYWORDS FUNDAMENTAL RIGHTS; FREEDOMS; SOCIAL RIGHTS; INTERNAL THEORY; EXTERNAL THEORY; LIMITS; RESTRICTIONS; SEPARATION OF POWERS.

Sumário: Introdução; 1. Dimensões, gerações ou espécies de direitos fundamentais; 2. As diferentes perspectivas entre os status nas relações de direitos fundamentais e as funções desses direitos; 3. Limitações ou restrições aos direitos fundamentais: as teorias interna e externa; 4. A aplicação da teoria externa aos direitos fundamentais de primeira dimensão; 5 . Os direitos fundamentais sociais prestacionais e a inaplicabilidade da teoria externa; 6 . Separação de poderes e as restrições: ponderação e a legitimidade da decisão; Referências. 


\section{INTRODUÇÃO}

Não há dúvida de que com o processo de constitucionalização dos países, a institucionalização dos direitos fundamentais tomou rumos concretos e possibilitou a sua efetiva normatização interna. Embora os direitos fundamentais, sob uma perspectiva clássica e histórica tenham tido origem na instrumentalização de institutos de proteção do indivíduo frente à atuação do Estado, vê-se cada vez mais que esse conceito não mais se sustenta, diante das constantes mudanças nas relações entre Estado e sociedade.

Embora os "direitos humanos" sejam considerados universais, para todos os povos e em todos os tempos, sob uma dimensão jusnaturalista, a doutrina tem sedimentado o entendimento no sentido de que os "direitos fundamentais" são aqueles, institucionalmente e juridicamente garantidos, com limitação no espaço e no tempo ${ }^{1}$. Aliás, a ordem mencionada por J.J. Gomes Canotilho não se restringe à Constituição, pois ele diferencia os "direitos fundamentais formalmente constitucionais" - enunciados por normas com valor constitucional formal - dos "materialmente fundamentais" - direitos constantes das leis aplicáveis de direito internacional não positivados constitucionalmente ${ }^{2}$.

Droits fondamentaux, expressão que restou cunhada na França de 1770, em meio ao movimento político e cultural que culminou na Declaração dos Direitos do Homem e do Cidadão de 1789, evoluiu nos últimos séculos para abarcar não só os direitos individuais, mas também os direitos sociais, econômicos e de solidariedade. Os novos enfoques, espécies, gerações ou dimensões, conforme expressões doutrinárias a serem adotadas pelo leitor e estudioso do direito, trouxeram um novo pensar sobre algumas questões, que vão desde a titularidade desses direitos fundamentais - sob o aspecto subjetivo do beneficiário do direito/norma, a sua eficácia jurídica e fática e, por fim, que buscam definir os limites ou restrições passíveis de serem impostas pelo ordenamento jurídico.

Norberto Bobbio chegou a apontar quatro dificuldades para a busca dos fundamentos absolutos dos direitos fundamentais ${ }^{3}$ : a) a primeira, no sentido de que a expressão "direitos do homem" possui conteúdos difíceis de se definir, porquanto desprovida de conteúdos objetivos e, quando esta é estabelecida, traz uma diversidade de possibilidades interpretativas, dependendo das posições ideológicas dos intérpretes e dos valores que permeiam as inúmeras situações; b) a segunda dificuldade consiste na constante mutação histórica e axiológica dos direitos fundamentais, de acordo com as necessidades e interesses na sociedade dentro de um contexto

1 CANOTILHO, J.J. Gomes. Direito constitucional e teoria da Constituição. Coimbra: Almedina, 2002.

2 Também nesse sentido, o escólio de COMPARATO, Fábio Konder. A afirmação histórica dos direitos humanos. São Paulo: Saraiva, 2001, p.56.

3 BOBBIO, Norberto. A era dos direitos. Rio de Janeiro: Campus, 1992, p.20. 
temporal e situacional; c) a terceira dificuldade está em se obter um fundamento absoluto para os direitos fundamentais, diante não só da heterogeneidade, mas também porque podem ser conflitantes entre si; d) a quarta e última dificuldade consiste na percepção de que existem alguns direitos fundamentais que configuram liberdades, que exigem muitas vezes do próprio Estado uma obrigação negativa, em antinomia a outros, que consistem no exercício de poderes estatais, que necessitam de uma atitude positiva para a busca de sua efetividade: e, portanto, torna muito difícil de se inferir pela existência de um fundamento político-jurídico absoluto que seja idêntico para todas as espécies, não havendo como construir um liame entre direitos antagônicos, pois, segundo Bobbio, "quanto mais aumentam os poderes dos indivíduos, tanto mais diminuem as liberdades dos mesmos indivíduos"4.

Trataremos, neste trabalho, de tentar desconstruir algumas verdades postas em manuais ou repetidas de forma automática pela doutrina e de realizar novas releituras a respeito das questões que envolvam as restrições aos direitos fundamentais, face as diversas concepções existentes sobre o tema e sob a perspectiva da interpretação constitucional.

Desde já há que se consignar que cinco são os vetores que serão considerados no desenvolvimento deste trabalho: a) em primeiro lugar, a necessária distinção de tratamento a ser dado aos direitos fundamentais decorrentes das liberdades clássicas de um lado e, de outro lado, aos direitos fundamentais de segunda dimensão; b) em segundo, de que inexistem direitos fundamentais absolutos; c) a interpretação da norma deve observar os critérios científicos, inclusive na definição da regra definitiva no caso de colisão de princípios de direitos fundamentais; d) a obrigação constitucional de evitar o abuso de direito; e) e, de se resguardar, sempre, a separação dos Poderes da República dentro dos parâmetros fixados em nossa Carta.

Buscaremos neste trabalho explicitar essas premissas e analisar a pertinência das teorias externa e interna quanto às restrições a essas duas espécies de direitos fundamentais (de primeira e de segunda dimensão), e descrever os limites a essas restrições, sem nos apartarmos da essência da Constituição Federal de 1988 e o equilíbrio imposto às funções dos Poderes instituídos de nossa República.

\section{DIMENSÕES, GERAÇÕES OU ESPÉCIES DE DIREITOS FUNDAMEN- TAIS}

Conforme escólio de Paulo Bonavides, o lema da revolução francesa veio a profetizar o que poderia ser considerado como uma sequência histórica da institucionalização dos direitos fundamentais, que no seu entender, decorre a sua divisão em três gerações, de forma sucessiva, a saber: direitos da liberdade, da igualdade e da fraternidade. ${ }^{5}$

4 Op. cit. p. 21.

5 Tive a oportunidade de discorrer sobre este tema no artigo "Titularidade dos Di- 
Seguindo lição de Karel Vasak, primeiro a escrever e divulgar de forma organizada a ideia anteriormente posta por Norberto Bobbio, como já percebido e alertado por Cançado Trindade ${ }^{6}$, os direitos de primeira geração correspondem aos direitos da liberdade, e foram os primeiros previstos constitucionalmente. Referemse aos direitos individuais civis e políticos, e possuem como fundamentos os direitos de resistência ou oposição contra a vontade estatal. À toda evidência decorreram da necessidade de se separar o Estado da sociedade e exigir daquele, principalmente, uma abstenção, um "non facere", visando reduzir ao máximo a interferência na liberdade dos indivíduos.

Conforme Norberto Bobbio, são direitos que reservam ao indivíduo uma esfera de liberdade "em relação ao" Estado e, no caso dos direitos políticos, concedem uma liberdade "no" Estado, pois permitem uma participação generalizada e real dos membros da sociedade no exercício do poder. Aqui são incluídos, como direitos fundamentais de primeira geração os direitos à vida, à liberdade - inclusive de manifestação, de locomoção e de associação, bem como o direito de igualdade de tratamento lato sensu (isonomia), em especial, pela própria lei, além do direito ao exercício do poder político.

Esses "direitos-liberdades", como salientado por Jean Rivero 7 , trazem no seu conteúdo essencial o aspecto negativo, dirigidos a uma abstenção estatal quanto ao exercício das liberdades individuais, coletivos e sociais. É claro que isto não implica na obstrução ao exercício do poder de polícia da Administração Pública, ou na possibilidade de uma normatização legislativa ou mesmo na regulação administrativa, mormente quando há o respeito aos direitos fundamentais na busca de uma ordem comum, um bem estar da coletividade. O que se impede é que a ação do Estado venha a violar os conteúdos mínimos e essenciais dos direitos fundamentais do indivíduo.

Os direitos da segunda geração são os sociais, culturais e econômicos, decorrentes do princípio da igualdade não só formal, mas em especial, material, visando o alcance da igualdade stricto sensu e surgiram, de fato, nos locais onde restou implantado o Estado Social. São direitos que exigem determinadas prestações por parte do Estado, impondo obrigações de fazer, "de facere", que hoje tem sido objeto de intensa produção científica sobre o seu conteúdo jurídico e sobre os graus de efe-

reitos Fundamentais Difusos e Coletivos". In, KIM, Richard Pae; BARROS, Sérgio Resende de; KOSAKA, Fausto Kozo Matsumoto. Direitos Fundamentais Coletivos e Difusos: questões sobre a fundamentalidade. São Paulo: Verbatim, 2012, p. 11 a 24.

6 Palestra proferida durante o "Seminário Direitos Humanos das Mulheres: A Proteção Internacional". Disponível na internet: http://www.dhnet.org.br/direitos/militantes/cancadotrindade/cancado_bob.htm. Acesso em 10.11.2014.

7 RIVERO, Jean \& MOUTOUH HUGUES. Liberdades Públicas I. São Paulo: Martins Fontes, 2009. 
tividade e/ou de aplicabilidade das normas que visam garanti-las.

No Brasil, por exemplo, o art. $5^{\circ}, \S 1^{\circ}$, da CF, que estabeleceu a auto-aplicabilidade das normas definidoras dos direitos e garantias fundamentais, vem sendo interpretado de forma a alcançar também os direitos sociais que, de forma geral, mas não de forma taxativa, estão elencados no artigo $6^{\circ}$, caput, da Constituição Federal, e que são, à toda evidência, também fundamentais.

Conforme raciocínio de Norberto Bobbio, os direitos de liberdade são os que devem ser garantidos "através" ou "por meio" do Estado. É fato que os direitos fundamentais de segunda dimensão acabaram por passar por um "ciclo de baixa normatividade", como já salientado por autores como Paulo Bonavides, ou tiveram eficácia duvidosa, eis que, diante de sua própria natureza de direitos a prestações materiais, nem sempre foram considerados resgatáveis pela sua baixa concretude, pela carência de recursos ou, ainda, pela limitação essencial de vontade política.

Sob o manto da fraternidade, passou a doutrina a considerar a existência de direitos fundamentais de terceira geração, muitos consistentes nos chamados direitos difusos e coletivos, transindividuais, os quais tem como objeto a proteção do ser humano, e não apenas de determinado indivíduo ou do Estado em favor da coletividade. Na lição de Ingo Wolfgang Sarlet, lembrando o próprio Kant, há que se respeitar "o caráter intersubjetivo e relacional da dignidade da pessoa humana, sublinhando inclusive a existência de um dever de respeito no âmbito da comunidade dos seres humanos"s.

Aliás, a atribuição da denominação de "direitos de solidariedade" ou de "fraternidade" aos direitos da terceira geração é a consequência da sua implicação universal, como é o caso do direito a um meio ambiente sustentável e equilibrado, na medida em que, como lembra Ingo Wolfgang Sarlet, "sempre haverá como sustentar a dignidade da própria vida de um modo geral, ainda mais numa época em que o reconhecimento da proteção do meio ambiente como valor fundamental indicia que não mais está em causa apenas a vida humana, mas a preservação de todos os recursos naturais, incluindo todas as formas de vida existente no planeta, ainda que se possa argumentar tal proteção da vida em geral constitua, em última

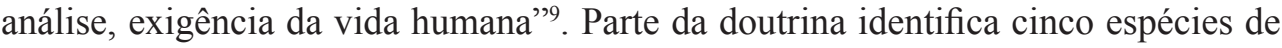
direitos como sendo de terceira geração, quais sejam: o direito ao desenvolvimento, à paz, ao meio ambiente, à propriedade sobre o patrimônio comum da humanidade e o de comunicação. Entretanto, cuida-se de senso comum o entendimento de que este rol deve ser estendido na medida em que os processos de universalização forem se desenvolvendo e de globalização fundado em normas insculpidas em tratados e acordos internacionais.

Alguns autores, como Paulo Bonavides, vem admitido também a existên-

8 SARLET, Ingo Wolfgang. Dignidade da pessoa humana e direitos fundamentais. Porto Alegre: Livraria do Advogado, 2008, p. 55.

9 Op. cit., p. 35. 
cia de direitos fundamentais de quarta geração, em decorrência da expansão da globalização econômica neoliberal, cuja filosofia de poder é negativa e que busca com mais intensidade a dissolução dos Estados nacionais e a redução dos fundamentos do conceito de soberania, como seriam os chamados direitos à democracia, à informação e ao pluralismo. Embora não aceito pelos doutrinadores de forma pacífica, lembra Paulo Bonavides que os direitos de quarta geração "compendiam o futuro da cidadania e o porvir da liberdade de todos os povos. Tão somente com eles será legítima e possível a globalização política"10. Ressalte-se que, para o autor, esses direitos de quarta dimensão, como é o caso do direito à democracia, ao pluralismo e à informação, estariam consagrados no Preâmbulo, no Título I (Dos Princípios Fundamentais) e no Título II (Dos Direitos e Garantias Fundamentais) da Constituição Federal de 1988.

Alguns autores estão a criticar a utilização da expressão "gerações", preferindo o uso do termo "dimensões" como é o caso da posição adotada por Ingo Wolfgang Sarlet, que chegou a salientar que "o reconhecimento progressivo de novos direitos fundamentais tem o caráter de um processo cumulativo, de complementaridade, e não de alternância, de tal sorte que o uso da expressão 'gerações' pode ensejar a falsa impressão de substituição gradativa de uma geração por outra." "11 Trata-se, entretanto, de uma discussão apenas terminológica, pois o conteúdo do conceito de cada uma das "dimensões", "espécies" ou "gerações" tem se pacificado na doutrina, ao menos até a terceira dimensão, e a utilização de uma ou outra terminologia em nada modifica a natureza jurídica de cada grupo de direitos fundamentais.

Parece evidente que a classificação, sob o aspecto científico, não deve levar em conta a cronologia em que os direitos foram paulatinamente conquistados pelas nações, mesmo porque o ciclo histórico de cada país diverge, bem como o processo de implantação dos seus direitos fundamentais. Ademais, uma geração, ou dimensão de cada espécie de direito fundamental não substitui a outra, mas se completa. Ficaremos com a terminologia "dimensão", para não nos afastarmos do entendimento que aparentemente vem ganhando mais corpo em nossa doutrina.

\section{AS DIFERENTES PERSPECTIVAS ENTRE OS STATUS NAS RELAÇÕES DE DIREITOS FUNDAMENTAIS E AS FUNÇÕES DESSES DIREITOS}

As liberdades públicas adquiriram configuração mais complexa do que

10 BONAVIDES, Paulo. Curso de direito constitucional. São Paulo: Malheiros, 2008, p. 530 e segs. Há autores que se referem a essa categoria, mas ainda não há consenso na doutrina sobre qual o conteúdo desse tipo de direitos. Há quem diga tratarem-se dos direitos de engenharia genética, enquanto outros se referem à luta pela participação democrática. Por isso mesmo, mostra-se discutível a importância dessa categoria, como já salientado por Sérgio Resende de Barros.

11 Op. cit., p. 68. 
aquelas dos séculos XVII e XVIII que, inclusive, inspiraram a Revolução Francesa, e a evolução das liberdades decorreu do respeito à necessidade de enfrentar novas ameaças e desafios postos a partir do século XIX. Essa transmudação ampliativa não só adveio da modificação do conceito de Estado e do seu papel, como também da relação entre o indivíduo e aquele. Isso não quer dizer que os direitos clássicos tenham desaparecido. Perderam estes apenas o seu caráter limitado vinculado às liberdades e à igualdade e alcançaram outros direitos, além de se verem limitados à obrigatória compatibilização com outros princípios constitucionais.

A passagem do individualismo exacerbado para o reconhecimento da existência de direitos de alguns grupos sociais, em especial, após as manifestações que resultaram na elaboração de constituições republicanas, ficou mais evidente com a Declaração Universal dos Direitos do Homem de 1948, que tratou de quatro ordens de direitos individuais: direitos pessoais do indivíduo, direitos do indivíduo em face das coletividades, liberdades públicas e direitos públicos, e os direitos econômicos e sociais, estes decorrentes do amadurecimento de novos valores e de exigências ligadas ao bem-estar por meio do Estado.

Esse novo olhar para os direitos fundamentais - clássicos e novos - exigiu da doutrina a elaboração de novas classificações e teorias relacionais, dentre elas, a teoria dos quatro status de Georg Jellinek, que pode ser resumido da seguinte maneira: a) o status passivo é aquele em que o indivíduo encontra-se em posição de subordinação com relação aos poderes públicos, razão pela qual o Estado tem competência para vincular o indivíduo por meio de mandamentos e proibições; b) o status ativo representa o poder do indivíduo de interferir na formação da vontade do Estado, o que se dá, em regra, pelo exercício dos direitos políticos concretizados não só pelo voto, mas também por outros instrumentos de participação de direta (por exemplo, o referendo e o plebiscito); c) o status negativo representa o espaço que o indivíduo possui para agir de forma livre, sem que ocorra a interferência estatal, ou seja, de se autodeterminar sem qualquer ingerência estatal; d) e, por fim, o status positivo, que consiste na possibilidade de o indivíduo exigir atuações positivas do Estado em seu favor, como ocorre, por exemplo, nos direitos econômicos e sociais que só podem ser exercidos com a implantação de políticas públicas específicas.

Essa teoria também se relaciona com as funções dos direitos fundamentais, conforme trabalho desenvolvido por J. J. Gomes Canotilho, que os classifica da seguinte maneira: função de defesa ou de liberdade; função de prestação social; função de proteção perante terceiros; e função de não discriminação ${ }^{12}$. Vejamos.

A função de defesa ou de respeito às liberdades, em regra vinculada aos direitos fundamentais de primeira dimensão, impõe ao Estado um dever de abstenção, ou seja, de não-interferência ou de não-intromissão, havendo esta dupla dimensão na leitura do constitucional português: "(1) constituem, num plano jurídico-objectivo,

12 Direito Constitucional e Teoria da Constituição. Coimbra: Almedina, 2002, p. 407-410 
normas de competência negativa para os poderes públicos, proibindo fundamentalmente as ingerências destes na esfera jurídica individual; (2) implica, num plano jurídico-subjectivo, o poder de exercer positivamente direitos fundamentais e de exigir omissões dos poderes públicos, de forma a evitar agressões lesivas por parte dos mesmos (liberdade negativa)"13.

A função de prestação social garante ao indivíduo ou à coletividade, normalmente, o direito de obter uma ação positiva do Estado, impondo-se a este um dever de agir previamente imposto pela Constituição e/ou por regras infraconstitucionais.

A função de proteção a fim de que, na conflituosidade da vida cotidiana, os direitos fundamentais não sejam violados, não só pela omissão ou por ato comissivo do Estado, mas também contra atos violadores que sejam praticados pelos próprios membros da sociedade, diante da eficácia horizontal dos direitos fundamentais.

A função de não discriminação, corolário do princípio da igualdade, visa assegurar que o Estado trate os seus cidadãos como sendo fundamentalmente iguais, o que exige que se busque, por todas as vias estatais (legislativa, administrativa ou mesmo judicial), que se garanta a igualdade material sempre que necessário.

Há que se salientar que a teoria do status de Jellinek, embora não tenha sido construída para caracterizar os direitos fundamentais, uma vez que desenvolvida a fim de apontar a posição do indivíduo em face do Estado e as situações que eventualmente possam decorrer dessa relação na definição dos seus respectivos direitos e deveres, serviu como importante instrumento político-científico a possibilitar a identificação das espécies e funções dos direitos fundamentais ${ }^{14}$. Aliás, a mim me parece evidente que essas teorias se encontram em planos simétricos, em que podem ser observadas, embora sob perspectivas diferentes, as relações jurídicas e as finalidades dos vários enunciados de direitos fundamentais. Anote-se que a identificação de uma função ou a identificação da natureza de uma determinada relação jurídica entre indivíduo(s) e o Estado será sempre dinâmica, na medida em que, na análise sobre um determinado direito fundamental, a conclusão quanto à sua posição jurídica dentro de um contexto específico há de ser obtida sempre sob a perspectiva da relação subjetiva e da função que se está a debater, considerados os elementos jurídicos e fáticos que envolvam a relação.

Como se sabe, os direitos fundamentais são compostos por princípios e regras, conforme escólio de Robert Alexy. E, como já alertado por Friedrich Müller, é comum que a interpretação sobre a aplicação desses direitos não seja baseada exclusivamente na subsunção, mas na interpretação constitucional - mesmo porque esses princípios se encontram na Carta constitucional de cada país. Também ao aplicador

13 Op. Cit, p. 407.

14 MENDES, Gilmar Ferreira; COELHO, Inocêncio Mártires; BRANCO, Paulo Gustavo Gonet, Hermenêutica constitucional e direitos fundamentais. Brasília: Brasília Jurídica, 2002, p. 140. 
da norma incumbirá a tarefa de, seja este o destinatário ou o simples intérprete, na tarefa de concretização do direito, observar com acuidade a realidade social, na medida em que a norma jurídica não se limita ao seu texto. A normatividade há de ser concretizada mediante um processo estruturado e passível de verificação e de justificação intersubjetiva ${ }^{15}$.

Ao mesmo tempo, no entanto, não há que se olvidar que a norma deve exercer a sua função primária que é a regência da vida em sociedade, com segurança e respeito ao ordenamento jurídico como um todo. Aliás, como já escreveu Hans Kelsen, o direito é um conjunto de normas coativas, a provocar determinados comportamentos e a norma será sempre um "dever ser", um juízo hipotético que expressa uma disposição e/ou uma consequência jurídica e a sua eficácia estará sujeita ao cumprimento fático.

Por isso, a aplicação de uma norma, ainda que se constitua em princípio, não pode resultar de um processo interpretativo rico em subjetivismo e "decisionismo", ainda que sob o simples rótulo de "ponderação". Aliás, não é sem razão que há na nossa doutrina ampla crítica ao "ativismo judicial", no sentido daquela atividade jurisdicional que ultrapasse os limites da atividade judicante e que atinja de morte o princípio da separação de poderes ${ }^{16}$.

Aliás, quero antecipar meu entendimento no sentido de que o termo "ativismo judicial" deve ser concebido somente sobre essa óptica, não podendo concordar com aqueles que se utilizam desta terminologia, de forma imprópria, quando atribuem a esta expressão o sentido de que se trata de um papel "legítimo" do Poder Judiciário de interferir no sistema político para o fim de garantir direitos, ainda que se trate de direitos fundamentais.

Não há, no meu entender, sentido em dar nome a uma atuação que é (e deve ser) própria do Poder Judiciário, instituído como previsto na Constituição Federal, que prevê não só a competência deste poder em garantir a justiça de suas decisões, mas também os instrumentos processuais a possibilitar amplo controle jurisdicional de leis e de atos normativos, inclusive quando há omissão do poder público, como é o caso do(a): mandado de injunção, ação direta de inconstitucionalidade por omissão, arguição de descumprimento de preceito fundamental, dentre outros. Voltaremos a essa temática no desenvolver do trabalho.

\section{LIMITAÇÕES OU RESTRIÇÕES AOS DIREITOS FUNDAMENTAIS: AS TEORIAS INTERNA E EXTERNA}

Em momento algum na história da evolução jurídica, qualquer desses di15 MÜLLER, Friedrich. Métodos de Trabalho do Direito Constitucional. São Paulo: Max Limonad, 2000, p. 61 a 70.

16 Vide importante trabalho de RAMOS, Elival da Silva. Ativismo Judicial - Parâmetros dogmáticos. São Paulo: Saraiva, 2012. 
reitos restou considerado como sendo absoluto. Exatamente por isso é que se fala em possibilidade de limitação ou de restrição aos direitos fundamentais. Vejamos as diferentes perspectivas doutrinárias e suas consequências.

Como restrição ou limitação, há que se entender como sendo toda ação ou omissão de qualquer dos poderes públicos, ou mesmo do particular, que venha a reduzir um direito fundamental. Uma vez que os direitos fundamentais não são absolutos ou ilimitados, eles se encontram submetidos a uma série de condicionamentos, que podem ser denominados de limites ou restrições, e que delimitam o exercício válido de uma prerrogativa subjetiva em determinadas circunstâncias.

$\mathrm{Na}$ atualidade, a doutrina conseguiu, no meu entender, chegar a alguns denominadores quanto à distinção das teorias interna e externa dos direitos fundamentais, no que toca ao tema das restrições dos direitos fundamentais. Partiremos desses pressupostos, para depois ampliarmos a discussão.

Iniciemos pela teoria externa, eis que na atualidade parece haver um consenso na jurisprudência e doutrina nacional no sentido de que os princípios fundantes dos direitos fundamentais são considerados como mandamentos de otimização. Nessa linha de entendimento, ao direito serão cabíveis determinadas restrições, "desvantagens normativas externas", que poderão instituídas, sempre sob a concepção de que há uma distinção, conforme lições de Robert Alexy, entre posições "prima facie" e "posição definitiva", ou seja, que implica na passagem entre o direito não restringido para um direito restringido. Neste caso, o enfoque dos debates se concentrará - em regra - nos limites para a restrição.

Para os adeptos do jurista Friedrich Klein, por não existir um direito ilimitado, só podem existir sob o aspecto da lógica pura, definições de disposições de direitos fundamentais, com seu conteúdo determinado, o que afasta a possibilidade da sua restrição, na medida em que o direito já nasce com os seus limites imanentes - fronteiras implícitas e apriorísticas. A dúvida existirá sempre quanto ao conteúdo das normas de direitos fundamentais.

De antemão devo consignar a minha posição no sentido de que a nossa Constituição da República, por dispor de cláusulas gerais de liberdade e de igualdade, e enfatizar a obrigação ao respeito à sua máxima efetividade, nos obriga a adotar a teoria externa, ao menos aos direitos fundamentais de primeira geração.

\section{A APLICAÇÃO DA TEORIA EXTERNA AOS DIREITOS FUNDAMEN- TAIS DE PRIMEIRA DIMENSÃO}

Vejamos como se poderá dar a plena possibilidade de fruição por parte dos cidadãos dos seus direitos fundamentais decorrentes das liberdades clássicas, ainda que ocorram restrições legítimas e, mesmo quando definidos "deveres e obrigações, em sentido lato, que da necessidade da sua garantia e promoção resultam para o 


\section{Estado"17.}

As restrições podem ser em sentido amplo, de um lado, decorrentes das intervenções fáticas sobre direitos fundamentais e que podem nascer do respeito aos direitos fundamentais dos demais sujeitos, hipótese prevista, inclusive, no art. 32.2. da Convenção Americana sobre Direitos Humanos que estabelece que os direitos de cada pessoa se encontram limitados pelos direitos dos outros, pela segurança de todos e pelas justas exigências do bem comum em uma sociedade democrática.

De outro lado, temos as restrições formais, em sentido restrito, estas decorrentes de leis e de atos normativos legítimos. As restrições podem estar expressas na própria Constituição ou podem ser implícitas (restrições indiretamente constitucionais), que são aquelas cujas imposições se encontram autorizadas pela Constituição. Conhecidas como cláusulas de reserva explícitas, são no escólio de Robert Alexy, disposições jusfundamentais ou partes de disposições jusfundamentais que autorizam expressamente restrições ou outras intervenções.

É certo que a nossa Constituição Federal de 1988 não previu fórmulas de como instituir formalmente as restrições a esses direitos, diferentemente das Constituições da República Portuguesa e da Lei Fundamental de Bonn que, respectivamente em seus artigos 18 e 19, trataram dos denominados "limites dos limites" dos direitos fundamentais (Schranken-Schranken no direito alemão).

Para parte da doutrina, como sustentado por Luís Prieto Sanchís, as limitações (restrições para nós) se encontram submetidas a duas circunstâncias especiais: a cláusula do conteúdo essencial do direito fundamental em questão e a exigência de justificação para a limitação ${ }^{18}$.

Interessante consignar também as lições de Pieroth e Schlink, citados por Dimitri Dimoulis e Leonardo Martins, que descrevem o papel da restrição da discricionariedade legislativa, ao pontuar as sete categorias direta ou indiretamente positivadas no texto constitucional alemão. Entre as indiretamente positivadas estão: a) os próprios direitos fundamentais (na lógica da limitação dialética entre poder estatal e liberdade: os direitos fundamentais representam limites ao poder estatal, limites estes não absolutos, pois foram previstos no texto constitucional reservas legais além da possibilidade de direito constitucional colidente. Por sua vez, os direitos fundamentais limitam a possibilidade do legislador limitá-los para que a função limitadora em si do direito fundamental não reste sem objeto). b) A reserva de lei editada pelo Parlamento. c) O princípio do critério da proporcionalidade. As restrições (limites dos limites) positivados no art. 19, I e II, GG são: a) Garantia do núcleo essencial (art. 19, II, GG, cfr. a seguir no texto). b) A proibição de lei limitadora regulamentadora de caso concreto (art. 19, I, 1, GG). c) O mandamento de indicação explícita

17 NOVAIS, Jorge Reis. As Restrições aos Direitos Fundamentais Não Expressamente Autorizadas pela Constituição. Coimbra: Coimbra Editora, 2003, p. 157.

18 SANCHÍS, Luis Prieto. Justicia Constitucional y Derechos Fundamentales. Madrid: Editorial Trotta, 2003, p. 232 a 241. 
do direito fundamental a ser limitado pelo legislador (art. 19, I, 2, GG, interpretada porém restritivamente pelo TC alemão). d) A observância dos princípios de Estado de direito da clara determinação da hipótese normativa (Bestimmtheitsgebot)" $"$.

A doutrina brasileira, com fundamento nos precedentes de nossa Suprema Corte, tem concluído que são limites às restrições aos direitos fundamentais: a) o princípio da legalidade, devendo-se incluir neste item a reserva legal e a validade da norma restritiva; b) a proteção ao núcleo essencial dos direitos fundamentais; c) o princípio da proporcionalidade; d) e a proibição de restrições casuístas, esta fundada no sentido de justiça, segurança jurídica e no princípio da igualdade ${ }^{20}$.

É fato que o legislador constituinte não conseguiu e jamais conseguirá prever todas as possíveis hipóteses de colisão de direitos fundamentais, daí porque os critérios genéricos de restrição e dos seus próprios limites tem gerado constantes discussões e reavivado muitas vezes a dúvida quanto à adoção dessa teoria externa, que se encontra assentada no caráter liberal e individualista dos direitos fundamentais.

No tocante às liberdades clássicas, parece-me que a adoção da teoria interna possibilitaria por demais o âmbito de intervenção do Estado sobre o indivíduo, inclusive a causar um déficit na sua efetiva garantia, perigo este que só poderia ser afastado com uma melhor apreensão pelo intérprete do sistema constitucional e de um aprofundado estudo dos instrumentos metodológicos de definição das limitações e dos critérios científicos de hermenêutica constitucional.

Não há que se olvidar que as normas de direitos fundamentais possuem natureza de princípios, mas também de regras, e as posições jurídicas definitivas somente serão identificadas como direitos definitivos após correto processo de ponderação. A técnica da ponderação não se trata de um exercício fácil ao legislador, ao administrador ou ao intérprete, em especialmente, se não restar adotado um critério forte de distinção entre regras e princípios ${ }^{21}$. Este é o grande desafio nos dias atuais. Aproveito o ensejo para, neste ponto, ressaltar o entendimento esposado pelo Ministro Dias Toffoli, quando do referendo da medida cautelar na Ação Direta de Inconstitucionalidade $\mathrm{n}^{\circ}$ 4.451-DF, em julgamento realizado pelo Plenário do Supremo Tribunal Federal em 2/9/2010, trata de forma inteligente e sóbria sobre o perigo do exercício não criterioso da ponderação:

"Tenho convicções arraigadas sobre o problema da metodologia de interpretação e aplicação dos direitos fundamentais e de suas restrições. Trabalho com

19 DIMOULIS, Dimitri; MARTINS, Leonardo. Teoria Geral dos Direitos Fundamentais. São Paulo: Revista dos Tribunais. 2009, p. 151 e 152, nota 50.

20 Vide MENDES, Gilmar Ferreira; COELHO, Inocêncio Mártires; BRANCO, Paulo Gustavo Gonet. Hermenêutica Constitucional e Direitos Fundamentais. Brasília: Brasília Jurídica, 2002, p. 241 a 249.

21 NOVAIS, Jorge Reis. As Restrições aos Direitos Fundamentais Não Expressamente Autorizadas pela Constituição. Coimbra: Coimbra Editora, 2003, p. 344-345. 
conceitos que não se enquadram no neopositivismo e no neoconstitucionalismo. Ainda estou convencido da utilidade dos antigos conceitos de lógica formal de matriz neokantiana, que, por muito tempo, inspiraram os debates jusfilosóficos. O juiz deve ser um fiel seguidor das regras, obviamente atualizado por conceitos modernos da Hermenêutica contemporânea, especialmente a de índole constitucional.

Ao legislador é que se devem atribuir as margens de conformação, a ponderação de valores na elaboração das normas, porque resultantes de um debate democrático, pluralista, sujeito às críticas, às marchas e contramarchas da vida em sociedade e da arena partidária.

Tenho muito receio da principiolatria, que, no início deste novo século, parece substituir a antiga legislatria. Fala-se hoje em uma nova figura jurídica, a legisprudência, um direito nascido da mescla - muitas vezes espúria - entre as fontes democráticas da atividade legislativa e a criação jurisprudencial livre. Esse papel de agente ponderador, que escolhe entre valores, deve ser primordialmente cometido ao Legislativo. O juiz pode e deve interpretar o Direito com referência a valores. Isso não é mais posto em causa. No entanto, não se pode usar dos princípios como meio de substituição da vontade geral da lei pela vontade hermética, esotérica de um juiz, que, em diversas situações, busca modelos teóricos para ajustar exteriormente as conclusões internas a que ele chegou por meios obscuros e de impossível sindicância por critérios de aferição universal.

Dito isso, passo ao exame da questão posta nos autos sob o enfoque de construções teóricas da ponderação, apenas e tão somente para que se coloque a controvérsia dentro de seu universo epistemológico. Ou seja, mesmo utilizando o referencial teórico dos princípios, os resultados a que chegaremos deverão respeitar a ponderação do legislador.

Antes de ingressar no exame da estrutura das normas de direitos fundamentais, reforço essa ordem de ideias com o empréstimo de contributo da Literatura, com a pena universal de William Shakespeare, em sua obra "Medida por medida" (Measure for measure).

Nesse texto clássico, William Shakespeare coloca nas mãos do Duque de Viena o poder de vida e morte sobre os súditos. Baixa-se uma lei que pró́be a luxúria e uma personagem, Cláudio, é condenado por esse crime de luxúria, cuja pena é a decapitação. Sua irmã Isabela, uma jovem noviça, de grande beleza, sai do convento e procura a autoridade, Lord Ângelo, implorando pela vida de Cláudio.

Ao procurar Lorde Ângelo e pedir clemência a seu irmão, a noviça ouve da autoridade que a lei é inafastável e que Cláudio deve sofrer a pena capital pelo crime de luxúria.

Instantes depois, tomado pela beleza de Isabela, o juiz volta atrás em sua tese de dura lex sed lex e, afirmando-se como senhor da interpretação da norma, faz a proposta insidiosa: "Cláudio não morrerá, Isabel, se amor me derdes."

Em troca da liberdade do irmão, Isabela entrega sua honra e seu corpo à 
autoridade.

Em suma, a mesma lei inflexível, por meio de ponderação, pode ser flexibilizada, chegando-se a um resultado absolutamente diverso, conforme juízos subjetivos e incontroláveis da autoridade, em desapego à segurança jurídica da norma legal.

É esse o risco que se corre quando a ponderação judicial sobrepõe-se, de modo excessivo, aos parâmetros democráticos da legislação.

Encerro essa advertência, que serve para a demarcação de minhas convicções sobre o tema, com passagem de um grande jurista que há pouco integrou este Pretório, emprestando-lhe seu brilho e sua argúcia intelectual. Esse texto, de autoria de Eros Roberto Grau, publicado na revista Justiça e Cidadania, editada pelo histórico jornalista (e defensor das liberdades civis) Orpheu Santos Salles, é muito útil ao que ora se decide e se compatibiliza com a interpretação do arbítrio de quem decide com base em preconceitos ou em valores subjetivos, ao estilo do romance de William Shakespeare:

“(...) Juízes, especialmente os chamados juízes constitucionais, lançam mão intensamente da técnica da ponderação entre princípios quando diante do que a doutrina qualifica como conflito entre direitos fundamentais. Como contudo inexiste, no sistema jurídico, qualquer regra ou princípio a orientá-los a propósito de qual dos princípios, no conflito entre eles, deve ser privilegiado, essa técnica é praticada à margem do sistema, subjetivamente, de modo discricionário, perigosamente. A opção por um ou outro é determinada subjetivamente, a partir das pré-compreensões de cada juiz, no quadro de determinadas ideologias. Ou adotam conscientemente certa posição jurídico-teórica, ou atuam à mercê dos que detém o poder e do espírito do seu tempo, inconscientes dos efeitos de suas decisões, em uma espécie de "vôo cego", na expressão de RÜTHERS. Em ambos os casos essas escolhas são perigosas .

O que há em tudo de mais grave é, no entanto, a incerteza jurídica aportada ao sistema pela ponderação entre princípios. É bem verdade que a certeza jurídica é sempre relativa, dado que a interpretação do direito é uma prudência, uma única interpretação correta sendo inviável, a norma sendo produzida pelo intérprete. Mas a vinculação do intérprete ao texto --- o que excluiria a discricionariedade judicial --- instala no sistema um horizonte de relativa certeza jurídica que nitidamente se esvai quando as opções do juiz entre princípios são praticadas à margem do sistema jurídico. Então a previsibilidade e calculabilidade dos comportamentos sociais tornam-se inviáveis e a racionalidade jurídica desaparece"(GRAU, Eros Roberto. O perigoso artifício da ponderação entre princípios. Justiça e Cidadania, n. 108, p.1619, julho, 2009).

Essa concepção, que está desenvolvida com caráter mais abrangente em 
outra obra de Eros Roberto Grau, o Ensaio e discurso sobre a interpretação/aplicação do Direito (5 ed. São Paulo: Malheiros, 2009. p. 283 e ss.), merece registro e serve para se apresentar uma alternativa metodológica ao enfrentamento da questão. Esse sincretismo pode chegar à perda de legitimidade da jurisdição constitucional, como bem aponta Lênio Luiz Streck, quando aborda o problema das "decisões conforme a consciência" (cf. Verdade e consenso: constituição, hermenêutica e teorias discursivas da possibilidade à necessidade de respostas corretas em direito. 3. ed., rev., ampl. e com posfácio. Rio de Janeiro: Lumen Juris, 2009. passim)."

Dentre os limites às restrições dos direitos fundamentais, o princípio da proporcionalidade parece ser o que mais apresenta dificuldade de aplicação. Ficaremos na análise pontual deste item.

A proporcionalidade, evidentemente, há de ser observada não só pelo legislador, como também pelo destinatário da norma, a fim de que a interferência nos direitos fundamentais seja feita sempre na medida da absoluta necessidade e de forma adequada e proporcional (Verhaltnismassigkeit). A lógica da construção da norma, no entanto, muitas vezes não será a mesma no momento de sua interpretação, e sob esta perspectiva é que se pretende apresentar algumas reflexões, em especial, diante das constantes críticas que alguns têm feito ao excesso de judicialização ${ }^{22}$.

É conveniente apresentarmos o posicionamento de Walter Claudius Rothemburg, para quem a proporcionalidade é um critério, e não um princípio autônomo, por se tratar de um índice que permite aplicar uma técnica de solução de problemas de concorrência e conflito. Para o constitucionalista, se a proporcionalidade fosse um princípio, a própria proporcionalidade estaria sempre em concorrência com outro princípio, a exigir constante e adequada solução, numa sorte de composição necessária ${ }^{23}$. Bem acentua o autor que no conflito entre dois princípios, a proporcionalidade seria um terceiro a ser ponderado, o que geraria uma incongruência no sistema e, portanto, seria inadmissível.

O critério da proporcionalidade não está expresso na Constituição, mas na

$22 \mathrm{O}$ tema sobre a proporcionalidade já foi desenvolvida por mim e pelo co-autor, professor Moacir Menozzi Júnior, em que pudemos concluir que a ponderação só será cabível em hipóteses específicas, quando não for possível a identificação da posição definitiva de um direito fundamental e, desde que na aplicação do princípio da proporcionalidade, também sejam considerados os argumentos do legislador que instituiu as normas de direito fundamental. Parte desse trabalho está sendo aproveitado nesse capítulo (vide KIM, Richard Pae; MENOZZI JUNIOR, Moacir. Princípio da Proporcionalidade e Fundamentalidade - o sentido para o legislador e para o hermeneuta. Caderno de Direito, v. 12, série 22, 2012, p. 167-186).

23 Rothemburg, Walter Claudius. Princípios constitucionais. Porto Alegre: Sergio Antônio Fabris, 2003, p. 42 e 43. 
ideia do devido processo legal substantivo e na justiça; há que ser visto como um instrumento indispensável para a proteção dos direitos, em especial os fundamentais, visto que permite o controle da discricionariedade dos atos do Poder Público e a adequada ponderação nas hipóteses já especificadas. Com o uso da adequação, necessidade ou vedação do excesso e proporcionalidade em sentido estrito é possível que se conclua, inclusive, pela anulação ou declaração de nulidade de atos legislativos ou administrativos.

A correta interpretação constitucional precisa calcar-se no plano jurídico, de um lado, e, de outro, num plano político, garantindo o equilíbrio, posto que na análise da interpretação da norma constitucional espera-se dos órgãos constitucionais o ajuste do interesse público que revele o sentimento da coletividade e de justiça.

Sob a perspectiva acima narrada há que se ressaltar o trabalho do jurista $\mathrm{e}$ Ministro Luís Roberto Barroso (STF) quando destaca que a proporcionalidade funciona como um parâmetro hermenêutico capaz de orientar como uma norma jurídica deve ser interpretada e aplicada no caso concreto, mormente nos casos de incidência dos direitos fundamentais, para a melhor realização dos valores e fins do sistema constitucional. Repete-se, então, que ao Poder Judiciário é permitido invalidar atos legislativos ou administrativos quando não observada a adequação entre o fim perseguido e o instrumento empregado pela norma jurídica (adequação); quando a medida normativa não seja exigível ou necessária, havendo meio alternativo menos gravoso para chegar ao mesmo resultado (necessidade ou vedação do excesso); e quando não se manifeste o binômio custo-benefício, pois o que se perde com a medida normativa é de maior relevo do que aquilo que se ganha (proporcionalidade stricto sensu) ${ }^{24}$.

Segundo Humberto Ávila ${ }^{25}$, a aplicação da proporcionalidade dar-se-á em situações em que se constate uma relação de causalidade entre dois elementos empiricamente discerníveis, um meio e um fim, de tal modo que o intérprete do direito possa proceder ao exame de três parâmetros fundamentais e complementares: a adequação, a necessidade e a proporcionalidade em sentido estrito.

No tocante à interpretação quando haja colisão de princípios fundamentais, é importante ressaltar que a utilização do princípio da proporcionalidade, com a observação da necessidade e adequação, cuida-se de um instrumento de controle não só da atividade legislativa, mas também, da vida cotidiana quando ausente regra específica que possa se subsumir a uma determinada situação fática e que implique em restrição a direito(s) fundamental(tais). A função da proporcionalidade é essencial e indispensável, principalmente nas hipóteses de colisão e restrições de direitos fundamentais, diante da complexidade da natureza dos princípios fundamentais ante suas oscilações terminológicas e imprecisões conceituais.

A dificuldade na aplicação do critério da proporcionalidade no processo de

24 BARROSO, Luís Roberto. Interpretação e Aplicação da Constituição. São Paulo: Saraiva, 2002, p. 213 a 216.

25 ÁVILA, Humberto. Teoria dos princípios. São Paulo: Malheiros, 2005, p. 116 a 124. 
ponderação não deve impedir, a sua incidência. Aliás, como afirmado pela boa doutrina, "pode-se dizer que em muitos casos os critérios políticos confundem-se com critérios jurídicos, podendo o juiz adequá-los ao caso concreto" 26 .

Não há que se olvidar, ainda, que muitas vezes a proporcionalidade utilizada pelo legislador não será a mesma aplicada pelo intérprete da lei. O legislador, no exercício de sua atividade de construção de uma regra, ou até mesmo de um princípio - abstrato, impessoal, e que harmonize os interesses coletivos e individuais - por se tratar de atividade estatal, deve ter como escopo principal alcançar o interesse público.

A propósito, conforme lição dos grandes administrativistas e constitucionalistas, toda lei tem duas finalidades: uma finalidade ampla, que deve ser o interesse público, e outra, restrita ou estrita, que deve ser a específica prevista na lei para aquela situação. Isto não significa necessariamente que o legislador só buscará alcançar finalidades coletivas, públicas, por meio da edição da norma. O que está a se sustentar é a indissociabilidade da finalidade pública da norma, que não deve ser dirigida a interesses do indivíduo, mas que pode tutelar direitos individuais, do cidadão.

Há um aspecto que devemos, no entanto, considerar, e que se mostra essencial para se entender a dificuldade de se verificar a proporcionalidade da norma e os motivos pelos quais a aplicação deste princípio pode acarretar mudanças significativas em nosso sistema jurídico. Não só a função jurisdicional encontra-se limitada aos valores constitucionais, mas também a atividade legiferante.

No processo legislativo, a proporcionalidade da norma deve ser analisada dentro dos critérios jurídicos que podem estar contextualizados a um momento histórico, e não há dúvida de que este deve levar em conta não só os elementos jurídicos técnicos estabelecidos pela Constituição Federal, mas também as variáveis sociais da época de sua publicação e seus efeitos para o futuro. Como muitos autores já sustentaram, não há dúvida quanto à existência de uma mutação constitucional e mesmo das normas infraconstitucionais. Isto exige um exame permanente quanto à proporcionalidade da norma, desde seu nascedouro até sua revogação, derrogação ou ab-rogação. Inúmeros são os exemplos de que a proporcionalidade, quando da edição da norma, não permanece a mesma, principalmente após o decurso do tempo, como é o caso das mais recentes decisões judiciais que passaram a interpretar que as normas postas na Constituição não só possuem eficácia jurídica, como também possuem um conteúdo mínimo que deve ser atingido no atendimento proporcional aos direitos do cidadão.

Assim sendo, embora a Constituição Federal não tenha sofrido modificações no tocante ao acesso universal e gratuito ao ensino fundamental, bem como às regras que garantem o acesso universal e gratuito à saúde pública, podemos observar como as recentes decisões dos tribunais têm reconhecido o direito ao pleno acesso a

26 STUMM, Raquel Denize. Princípio da proporcionalidade no direito constitucional brasileiro. Porto Alegre: Livraria do Advogado, 1995, p. 83-85. 
esses serviços públicos, o que não vinha sendo concedido pelo Judiciário pelo menos até o final do século passado.

Mostra-se, inclusive, importante a análise da exposição de motivos, as justificativas apresentadas pelo proponente de um projeto de lei ou até mesmo os pareceres apresentados pelas comissões e subcomissões, para analisar não só a validade da norma, mas as hipóteses de sua incidência. $\mathrm{O}$ tempo e as mudanças das variáveis que compuseram a proporcionalidade da norma sancionada, por exemplo, poderão autorizar que o hermeneuta, observando este princípio da proporcionalidade, chegue a conclusões absolutamente díspares em relação à aplicação originária deste princípio quando da elaboração e publicação da norma.

Em nosso entender, a fim de que haja segurança jurídica, efetivo respeito ao estado democrático de direito e observação à separação de poderes, além da aplicação das regras de interpretação constitucional e da observância à hermenêutica tradicional, o intérprete deve respeitar a vinculação entre a lei da ponderação e a teoria da argumentação jurídica racional e deve privilegiar a lei, resultado do processo democrático. Ou seja, em não tendo havido grandes variáveis fáticas, há que prevalecer a proporcionalidade da norma observada pelo legislador.

É fato que ainda não conseguimos solucionar o problema do sincretismo metodológico a que se refere o eminente professor Virgílio Afonso da Silva ao tratar dos curto-circuitos existentes em nossa doutrina a respeito da interpretação constitucional. Entretanto, concordando com o autor, o hermeneuta deve escolher um dos métodos de interpretação constitucional normalmente apresentados pela doutrina e aplicar os cânones de interpretação sistematizados por Savigny, que também devem valer para o Direito Constitucional ${ }^{27}$.

\section{OS DIREITOS FUNDAMENTAIS SOCIAIS PRESTACIONAIS E A INAPLICABILIDADE DA TEORIA EXTERNA}

Inicio este capítulo com uma afirmativa: não há como se aplicar a teoria externa aos direitos fundamentais de segunda geração que exijam prestações positivas do Estado.

Aliás, todos aqueles que se debruçaram efetivamente sobre tema sabem os motivos pelos quais esta premissa se torna evidente quando se trata de direitos fundamentais vinculados a uma ação prestacional do Estado, ou seja, na relação de um status positivo, sob a óptica de Friedrich Muller.

Em nossa Constituição Federal, os direitos fundamentais sociais se encontram, sobretudo, contemplados nos artigos $6^{\circ}, 7^{\circ}, 170$, dentre outros. No que toca aos dispositivos que tratam da Justiça Social, podemos observar que seu ordenamento

27 SILVA, Virgílio Afonso da. Interpretação constitucional. (Org.). Malheiros: São Paulo, 2007, p. 142. 
jurídico encerra além de princípios, normas de aplicabilidade imediata, valores e disposições fundamentais, também as normas de direitos sociais que possuem eficácia limitada, ou seja, que exigem a edição de normas organizacionais e procedimentais a viabilizar a execução da conduta positiva imposta pela Carta.

A configuração de um direito fundamental de segunda dimensão, no entanto, não prescinde da conjugação dos princípios com as normas infraconstitucionais, como já acentuado por Agustín Gordillo, que assim salientou:

"Diremos entonces que los princípios de derecho publico contenidos ne la Constitución son normas jurídicas, pero no sólo eso: mientras que la norma es um marco dentro del cual existe uma certa libertad, el principio tiene sustância integral. La simple norma constitucional regula el procedimento por el que son producidas las demás normas inferiores (ley, reglamento, sentencia) y eventualmente su contenido; pero esa determinación nunca es completa, ya que la norma superior no puede ligar em todo sentido y em toda dirección el acto por el qual es ejecutada; ela principio, em cambio, determina em forma integral cual há de ser la sustância del acto por el cual se lo ejecuta" 28 .

Como afirmado pelo jurista Celso Antônio Bandeira de Mello, ao analisar alguns dos incisos dos artigos $7^{\circ}$ e 170 da Constituição Federal, determinados princípios e regras constitucionais pertencem à categoria do que ele referiu como "explicitações de fins, sem indicação dos meios previstos para alcançá-los". Essas normas não chegam a conferir aos cidadãos uma utilidade substancial, concreta, desfrutável positivamente e exigível quando negada. Entretanto, não deixam de ser fontes de direitos e possuem alguma eficácia, na medida em que possuem o alcance de

“a) proporcionar aos administrados a possibilidade de se oporem judicialmente ao cumprimento de regras e à prática de comportamentos adversos ao estatuído na Carta do pais, além de b) imporem ao Judiciário, quando da interpretação e dicção do Direito nos casos concretos, decisões que convirjam na mesma direção e sentido destes preceitos - resultando daí a pretendida proteção constitucional aos administrados"29

Ao concluir esse autor sobre o tema, acaba por elencar de forma percuciente as três espécies tipológicas de normas constitucionais atinentes aos direitos sociais: "a) algumas são concessivas de poderes jurídicos, os quais podem ser exercita-

28 GORDILLO, Agustín. Introducción al Derecho Administrativo. Buenos Aires: Abeledo-Perrot, 1966, p. 176 e 177.

29 MELLO, Celso Antônio Bandeira de. Eficácia das normas constitucionais e direitos sociais. São Paulo: Malheiros, 2010, p. 48. 
dos de imediato, com prescindência de lei; b) outras são atributivas de direito a fruir, imediatamente, benefícios jurídicos concretos, cujo gozo se faz mediante prestação alheia que é exigível judicialmente, se negada; c) outras, que apenas pontam finalidades a serem atingidas pelo Poder Público, sem indicar a conduta que as satisfaz, conferem aos administrados, de imediato, direito de se oporem judicialmente aos atos do Poder Público acaso conflitantes com tais finalidades"30.

Ressalte-se que o simples fato das normas constitucionais, programáticas ou não, gerar alguma eficácia a propiciar níveis diversos de direitos subjetivos - o que é absolutamente normal em função do princípio da máxima efetividade das normas constitucionais - não impede que se reconheça a prevalência, nesta categoria de direitos de segunda dimensão, das normas de eficácia limitada. Portanto, em regra, os direitos sociais só podem ser efetivamente exercitados quando o poder público coloca à disposição do usuário um serviço e quando vem a cumprir com obrigações constitucionais e infraconstitucionais instituídos por uma política pública social, tudo em virtude de um de seus elementos caracterizadores, qual seja, a "função promocional do Estado" ${ }^{31}$.

Por isso, respeitados juristas como J.J. Canotilho e Vital Moreira já sustentaram que descabe falar em restrições de direitos prestacionais, ainda que impliquem em direitos fundamentais, na medida em que, nesta categoria de direitos fundamentais, só será possível discutir-se a respeito da concretização (plena, suficiente ou insuficiente) da norma constitucional. Essa conclusão fica evidente quando não há, no universo dos direitos sociais prestacionais, como identificar os mandamentos de otimização.

Mesmo quando um país vem a inserir em seu texto constitucional um direito social de eficácia plena, o que ocorre normalmente com alguns direitos do trabalho e previdenciários, muito similares aos direitos de defesa, não se tratará de um princípio que possa ser considerado um mandamento de otimização. Cuidar-se-á de norma com natureza jurídica de regra de direito fundamental.

Portanto, na interpretação de uma norma constitucional de direito fundamental social, parece correto infirmar que o intérprete verificará o conteúdo jurídico do direito social, e não, a limitação ou a restrição do direito, o que será identificável sempre sob o cotejo dos princípios e regras constitucionais e infraconstitucionais que estão a formar o direito social exercitável pelo usuário do serviço ou da atividade pública.

Isso não significa que não seja possível verificar a ocorrência de inconstitucionalidade pela omissão estatal, ou afirmar-se pela impossibilidade de se ponderar. Pelo contrário. A ponderação, no nosso modesto entender, não se aplica apenas às hipóteses em que haja colisão de direitos fundamentais, mas também quando estão

30 Op. Cit., p. 56.

31 SCHÄFER, Jairo. Classificação dos direitos fundamentais. Porto Alegre: Livraria do Advogado, 2013, p. 55. 
em jogo valores constitucionais - antagônicos ou não - como é o caso em que o intérprete deva analisar um direito fundamental em cotejo com a democracia participativa, o interesse público, a segurança jurídica, o interesse coletivo, a justiça social, etc.

Não se está a olvidar o escólio de Jorge Reis Novais, no sentido de que se deve entender a restrição como "[...] a acção ou omissão estatal que afecta desvantajosamente o conceito de um direito fundamental, seja porque se eliminam, reduzem ou dificultam as vias de acesso ao bem nele protegido e as possibilidades da sua fruição por parte dos titulares reais ou potenciais do direito fundamental seja porque se enfraquecem os deveres e obrigações, em sentido lato, que da necessidade da sua garantia e promoção resultam para o Estado" 32 . Pelo contrário; afirma-se e reitera-se que essa concepção de restrição não caberá aos direitos fundamentais sociais, ainda que tenha ocorrido a omissão abusiva estatal, uma vez que não existirá, na espécie, um mandamento de otimização a ser objeto de restrição. O que pode ocorrer nessas hipóteses é a inconstitucionalidade pelo descumprimento de obrigação pública constitucional a afetar um direito fundamental social definido por um conteúdo jurídico composto por normas - constitucionais e inconstitucionais.

Poderíamos perguntar se no caso dos direitos fundamentais sociais o correto seria adotar-se a teoria interna dos direitos fundamentais (?). A mim me parece que a resposta há de ser positiva.

Embora entenda que no caso dos direitos fundamentais sociais prestacionais, ao invés da terminologia "limitação ao direito social" o ideal seria a utilização da expressão "delimitação do conteúdo do direito social", pois o direito social é conformado de acordo com os preceitos da Constituição, e não, limitado, a teoria interna parece responder melhor ao ordenamento jurídico vigente no caso dos direitos de segunda dimensão.

O fato é que, independentemente da nomenclatura que se dê - limitação ou delimitação do direito social - haverá sempre na ação positiva estatal, determinados limites imanentes, fronteiras implícitas e apriorísticas, inseridas na própria Carta constitucional e de outros que serão definidos pelo legislador competente no âmbito infraconstitucional. Portanto, a eficácia desses direitos estará condicionada à execução das políticas públicas decorrentes dos processos legislativo, orçamentário, administrativo e, até mesmo e se o caso, de um processo judiciário.

\section{SEPARAÇÃO DE PODERES E AS RESTRIÇÕES: PONDERAÇÃO E A LEGITIMIDADE DA DECISÃO}

Como restou anteriormente salientado, a restrição ou a limitação aos direitos fundamentais deve observar os requisitos da legalidade, da proporcionalidade e da proibição das decisões casuísticas. Também deve sempre existir respeito ao

32 Op. cit., p. 82 a 83. 
núcleo essencial do direito fundamental em pauta e do mínimo existencial, este vinculado mais especificamente aos direitos sociais ${ }^{33}$.

À toda evidência lógica, a restrição há de ser interpretada e aplicada de forma restritiva, razão pela qual ela ocorrerá nos casos em que houver efetiva necessidade e desde que o titular da função que a institua, ou a aplique, cumpra o já referido trinômio: necessidade, adequação e proporcionalidade. Algumas serão instituídas por lei, é o caso do direito à inviolabilidade de correspondência, prevista no artigo $5^{\circ}$, inciso XII da Constituição Federal, que pode ser objeto de restrição explicitamente escolhida pela própria Carta nos casos de Estado de Defesa e de Estado de Sítio; ou mesmo pelo administrador quando se tratar de correspondências que devam passar por alguma espécie de fiscalização (raio-x, v.g.) porque existente algum interesse público como é o caso da fiscalização em aeroportos, penitenciárias ou em órgãos que exijam maior segurança.

Embora o Poder seja uno e indivisível, pois pertence ao povo brasileiro como expresso na Constituição Federal, não há dúvida de que os Poderes instituídos (Legislativo, Executivo e Judiciário), no exercício das funções republicanas, devem respeito um ao outro e a harmonia há de ser respeitada. No paradigmático voto do Ministro Dias Toffoli, no mencionado julgamento da ADI n ${ }^{\circ} 4.451 \mathrm{MC}-\mathrm{REF} / \mathrm{DF}$, restaram acentuadas importantes advertências aos atores que efetivam as ponderações na análise das restrições aos direitos e que merecem ser destacadas, a saber:

"A chamada colisão de princípios é por demais conhecida pela Filosofia do Direito contemporânea, graças à contribuição do jurista Robert Alexy. Não se fala de invalidação de um princípio por outro, mas de sua prevalência, conforme as circunstâncias e segundo a fórmula-peso (ALEXY, Robert. Theorie der Grundrechte (Teoria dos Direitos Fundamentais). Frankfurt am Main: Suhrkamp, 1986 p. 78-79).

A lei de colisão (Kollisionsgesetz) baseia-se no primado de que "as condições sob as quais um princípio precede aos outros, formam o tipo abstrato de uma regra que expressa as conseqüências jurídicas do princípio precedente" (ALEXY, Robert. Theorie der Grundrechte... p. 79-84).

Assim, a ponderação de princípios leva, na prática, à produção de uma norma cuja formulação conduz ao que Robert Alexy chama de fundamentação jurídico-fundamental correta.

Como decorrência, não há falar-se em direitos fundamentais absolutos. Como bem salienta Herbert Bethge, "a noção de um direito fundamental ilimitado é impossível na prática e contraditória na teoria" (In. Die verfassungsrechtliche Problematik der Grundpflichten. Juristische Arbeitsblätter, Heft 5, p. 252, 1985).

E, nesse sentido, a liberdade, qualquer que seja ela, inclusive a de expressão, é ilimitada prima facie, mas limitada como direito definitivo.

33 Esse tema será objeto de abordagem em outro artigo. 
Essa restrição a um direito fundamental pode e deve ser feita primordialmente pelo legislador. Não é adequado supor que haveria pré-condicionamento ao legislador e ampla deferência ao juiz para restringir direitos fundamentais, apenas porque o magistrado atua no caso concreto e sob circunstâncias de fato. O legislador goza da legitimidade democrática. É eleito. Submete-se aos constrangimentos do processo eleitoral, às quizílias partidárias, às contradições do Parlamento, às pressões organizadas e ao risco permanente de ser exautorado da vida pública, por meio da censura periódica de seus representados nas urnas. Negar-lhe essa prerrogativa é atrofiar o Estado Democrático de Direito.

Toda restrição ao direito fundamental é uma forma de se criar obstáculos à realização plena de um princípio, como adverte Robert Alexy (Op. cit. p.300-307). E a isso deve corresponder uma atuação fundamentada, por cuidar de norma restritiva. Mas esse espaço existe. É o espaço para conformação do legislador ordinário. É frequente, nesse sentido, a presença de reservas explícitas (Gesetzvorbehalte) que se identificam pela terminologia clássica "nos termos da lei", "na forma da lei" ou "conforme a lei". (...)

Existem também reservas implícitas decorrentes de uma autorização tácita ou imanente de uma restrição que se confere ao legislador ordinário, como admitem Robert Alexy e Christian Starck. Isso é uma decorrência do princípio da unidade da Constituição, tão bem defendido na doutrina alemã por Bernhard Schlink (Freiheit durch Eingriffsabwehr - Rekonstruktion der klassischen Grundrechtsfunktion. Europäische Grundrechte Zeitschrift, 11, Heft 17, p. 464, 1984) e já referido nas construções pretorianas desta Corte (ADI 815, Relator Min. Moreira Alves, Tribunal Pleno, julgado em 28/03/1996, DJ de 10/5/96).

A ponderação feita pelo legislador é legítima.

(...)

IV - NECESSIDADE DE DEBATE SOBRE A TRANSPARÊNCIA E A FUNDAMENTAÇÃO DAS RESTRIÇÕES A DIREITOS FUNDAMENTAIS. A AUTOCONTENÇÃO RETÓRICA.

O presente caso, Senhores Ministros, tem a oportunidade de nos permitir fazer o inadiável debate sobre o método e a técnica de restrição de direitos fundamentais.

Não pode a Corte simplesmente criar uma metodologia baseada em afirmações solenes e em juízos morais carregados de retórica, mas que não revelam a transparência dos motivos reais de suas próprias conclusões. É essa a crítica que modernos constitucionalistas como Cass Sunstein têm suscitado e que merecem nossa reflexão. 


\section{(...) \\ O mandato de conformação do legislador deve ser, como bem assinala Robert Alexy, fundamentado."}

Nos tempos atuais, em que se tornaram comuns as críticas às decisões do Poder Judiciário no sentido de que existiria excesso de subjetivismo e ausência de critérios científicos nos julgamentos, o que estaria a causar violação aos princípios da igualdade, da segurança jurídica e da separação de poderes, entendo que a par de alguns exageros, a Justiça e o sistema processual devem sofrer alguns ajustes, a fim de garantir o atendimento a esses três princípios.

Não há espaço neste trabalho a autorizar uma incursão aprofundada desses temas. Entretanto, acentuo que parece existir a necessidade de que alguns membros do Judiciário reavaliem os pressupostos que dão sustentação à separação das funções dos poderes instituídos a fim de que o equilíbrio previsto na Constituição Federal seja efetivamente respeitado. Seja no controle de constitucionalidade de uma norma, seja no exercício de uma ponderação pelo Judiciário, há de se respeitar sempre que necessário o forema jurídico "in dubio pro legislatore" 34 , ainda que haja uma zona de penumbra quanto à constitucionalidade ou não de uma decisão discricionária adotada pelo legislador. Nesta linha de raciocínio, dentro do "pensamento possibilista" de Peter Häberle, e na defesa da democracia, há que se respeitar as decisões legislativas, como também sustentado por Robert Alexy, Jeremy Waldron, Friedrich Klein, Ronald Dworkin, Christian Starck, Konrad Hesse, Kelsen e tantos outros juristas e filósofos - que em maior ou menor grau, acentuaram ser imperiosa adotar-se a perspectiva de que existe uma presunção primeira de legalidade e de legitimidade das opções feitas pelo legislador, sempre que respeitada a margem de ação indicada nos marcos constitucionais.

Isso não significa que o magistrado deva se manter insensível quanto às inovações hermenêuticas, inclusive em decorrência da evolução científica e jurisprudencial de outros países. Também a omissão ou a intervenção legislativa concretizadora não pode ser destituída de razoabilidade ou racionalidade a ponto de suprimir o direito individual escrito. Nesses casos, os magistrados e demais operadores do direito terão o dever constitucional de concretizar os direitos fundamentais pela via interpretativa, a fim de evitar a sua redução desproporcional, eliminação ou total ineficácia.

\section{REFERÊNCIAS}

ALEXY, Robert. Teoria da argumentação jurídica: a teoria do discurso racional como teoria da justificação jurídica. Trad. Zilda Hutchinson Schild Silva. São Paulo:

34 PULIDO, Carlos Bernal. El neoconstitucionalismo a debate. Bogotá: Instituto de Estudios Constitucionales, 2006, p. 17. 
Landy, 2008.

. Trad. Virgílio Afonso da Silva. Teoria dos Direitos Fundamentais. Malheiros: São Paulo, 2008.

AMARAL, Gustavo. Interpretação dos direitos fundamentais e o conflito entre poderes. Teoria dos Direitos Fundamentais. Rio de Janeiro: Renovar, 1999.

ANDRADE, José Carlos Vieira de. Os Direitos fundamentais na Constituição portuguesa de 1976. Coimbra: Almedina, 1998.

ÁVILA, Humberto. Teoria dos princípios. São Paulo: Malheiros, 2005.

BARROS, Suzana de Toledo. O Princípio da proporcionalidade e o controle de constitucionalidade das leis restritivas de direitos fundamentais. Brasília: Brasília Jurídica, 1996.

BARROSO, Luís Roberto. O Direito Constitucional e a Efetividade de Suas Normas. Limites e Possibilidades da Constituição Brasileira. Rio de Janeiro: Renovar, 2002.

Saraiva, 2002. . Interpretação e Aplicação da Constituição. São Paulo:

BOBBIO, Norberto. A era dos direitos. Rio de Janeiro: Campus, 1992.

BONAVIDES, Paulo. Curso de direito constitucional. São Paulo: Malheiros, 2008.

BUCCI, Maria Paula Dallari. Direito Administrativo e Políticas Públicas. São Paulo: Saraiva, 2002.

CANOTILHO, J. J. Gomes. Direito constitucional e teoria da Constituição. Coimbra: Almedina, 2002.

CASTRO, Carlos Roberto de Siqueira. O Devido processo legal e a razoabilidade das leis na nova constituição do brasil. Rio de Janeiro: Forense, 1989.

COMPARATO, Fábio Konder. A afirmação histórica dos direitos humanos. São Paulo: Saraiva, 2001.

DIMOULIS, Dimitri; MARTINS Leonardo. Teoria geral dos direitos fundamentais. São Paulo: Revista dos Tribunais, 2009.

DWORKIN, Ronald. Los derechos en serio. Barcelona: Ariel, 2002.

FARIA, José Eduardo. Direitos Humanos, Direitos Sociais e Justiça. São Paulo: Malheiros, 2002.

FARIAS, Edilsom Pereira de. Colisão de direitos: a Honra, a intimidade, a vida privada e a imagem versus a liberdade de expressão e informação. Porto Alegre: Sérgio Fabris, 1996. 
FERRAJOLI, Luigi. Derechos y garantías. La ley del más débil. Madrid: Trotta, 2006.

GORDILLO, Agustín. Introducción al Derecho Administrativo. Buenos Aires: Abeledo-Perrot, 1966.

HABERLE, Peter. Hermenêutica Constitucional: a sociedade aberta dos intérpretes da Constituição; contribuição para a interpretação pluralista e 'procedimental' da Constituição. Porto Alegre: Sergio Antonio Fabris Editor, 2002.

HESSE, Konrad. Elementos de Direito Constitucional da República Federal da Alemanha. Trad. Luís Afonso Heck. Porto Alegre: Sérgio Antônio Fabris, 1998.

JELLINEK, Georg. Teoria General del Estado. México: Fondo de Cultura Económica, 2000.

KELSEN, Hans. Teoria pura do direito. São Paulo: Martins Fontes, 1999.

KIM, Richard Pae; MENOZZI JUNIOR, Moacir. "Princípio da Proporcionalidade e Fundamentalidade - o sentido para o legislador e para o hermeneuta". In, Caderno de Direito, v. 12, série 22, 2012, p. 167-186.

KIM, Richard Pae. "Titularidade dos Direitos Fundamentais Difusos e Coletivos". In, KIM, Richard Pae; BARROS, Sérgio Resende de; KOSAKA, Fausto Kozo Matsumoto. Direitos Fundamentais Coletivos e Difusos: questões sobre a fundamentalidade. São Paulo: Verbatim, 2012, p. 11 a 24.

LASSALE, Ferdinand. A essência da Constituição. Rio de Janeiro: Lumen Juris, 2010.

MARMELSTEIN, George. Curso de Direitos Fundamentais. São Paulo: Atlas, 2008.

MELLO, Celso Antônio Bandeira de. Eficácia das normas constitucionais e direitos sociais. São Paulo: Malheiros, 2010.

MENDES, Gilmar Ferreira; Branco, Paulo Gustavo Gonet. Curso de Direito Constitucional. São Paulo: Saraiva, 2011.

MENDES, Gilmar Ferreira; COELHO, Inocêncio Mártires; BRANCO, Paulo Gustavo Gonet. Hermenêutica Constitucional e Direitos Fundamentais. Brasília: Brasília Jurídica, 2002.

MORAES, Alexandre de. Direito Constitucional. São Paulo: Atlas, 2012.

MÜLLER, Friedrich. Métodos de Trabalho do Direito Constitucional. São Paulo: Max Limonad, 2000.

PIOVESAN, Flávia. Temas de Direitos Humanos. $2^{a}$ ed. São Paulo: Max Limonad, 2003. 
PULIDO, Carlos Bernal. El neoconstitucionalismo a debate. Bogotá: Instituto de Estudios Constitucionales, 2006.

QUEIROZ, Cristina. Interpretação constitucional e poder judicial. Coimbra: Coimbra Ed., 2000. . Direitos Fundamentais Sociais. Coimbra: Coimbra, 2006.

RAMOS, Elival da Silva. Ativismo Judicial - Parâmetros dogmáticos. São Paulo: Saraiva, 2012.

RIVERO, Jean \& MOUTOUH, Hugues. Liberdade Públicas I. São Paulo: Martins Fontes, 2009.

ROTHEMBURG, Walter Claudius. Princípios constitucionais. Porto Alegre: Sergio Antônio Fabris, 2003.

ROSENFELD, Michel. The Identity of the Constitucional Subject. New York: Routledge, 2010.

ROSS, Alf. Sobre el derecho y la justicia. Buenos Aires: Universitaria de Buenos Aires, 1977.

SANCHÍS, Luis Prieto. Justicia Constitucional y Derechos Fundamentales. Madrid: Editorial Trotta, 2003.

SARLET, Ingo Wolfang. A eficácia dos direitos fundamentais: uma teoria dos direitos fundamentais na perspectiva constitucional. Porto Alegre: Livraria do Advogado, 2009.

Livraria do Advogado, 2008.

. Dignidade humana e direitos fundamentais. Porto Alegre:

SARMENTO, Daniel. Por um Constitucionalismo Inclusivo: história constitucional brasileira, teoria da Constituição e direitos fundamentais. Rio de Janeiro: Lumen Juris, 2010.

SCHÄFER, Jairo. Classificação dos direitos fundamentais. Porto Alegre: Livraria do Advogado, 2013.

SCHWAB, Jürgen. Cinqüenta anos de Jurisprudência do Tribunal Constitucional Alemão. Montevideo: Konrad Adenauer Stiftung, 2006.

SILVA. José Afonso da. Curso de Direito Constitucional Positivo. São Paulo: Malheiros, 2013.

SILVA, Virgílio Afonso da. A constitucionalização do direito: os direitos fundamentais nas relações entre particulares. São Paulo: Malheiros, 2008.

STUMM, Raquel Denize. Princípio da proporcionalidade no direito constitucional 
brasileiro. Porto Alegre: Livraria do Advogado, 1995.

VIEIRA, Oscar Vilhena. A Constituição e sua reserva de justiça. São Paulo: Malheiros, 1999.

ZAGREBELSKY, Gustavo. El derecho dúctil. Madrid: Trotta, 1995. 